\title{
Descrição das Condições Socioeconômicas e Processo de Produção da Farinha de Mandioca da Colônia do Pulador, Anastácio, MS
}

\section{Description of Socioeconomic Conditions and Production Process of Cassava Flour from Colônia do Pulador, Anastácio, MS}

\author{
George Elias Ayache; ; Denise Renata Pedrinhoa; José Francisco dos Reis Neto*a
}

aniversidade Anhanguera Uniderp, Programa de Pós-Graduação Stricto Sensu em Produção e Gestão Agroindustrial. MS, Brasil.

*E-mail: jose.rneto@anhanguera.com

\begin{abstract}
Resumo
Este artigo técnico analisou as condições socioeconômica e produtiva da Colônia do Pulador, para entender como é o processo de produção da farinha de mandioca. Apresentam-se as principais características produtivas, descrevendo o perfil educacional e familiar, administrativa, capacidade produtiva e uma breve discussão sobre os elementos facilitadores e complicadores, da produção e da comercialização da farinha de mandioca. Empregou-se uma pesquisa de abordagem qualitativa e quantitativa, com procedimento de campo, para entendimento da realidade investigada, com a coleta de dados juntos aos produtores familiares, observando-se o processo de produção e com entrevistas estruturadas, empregando-se um questionário, contendo os dados demográficos, infraestrutura básica da propriedade, processo produtivo, comercialização e assistência técnica. Os onze produtores, em sete casas de farinha, foram entrevistados, e os dados foram analisados com o emprego da estatística descritiva. Os resultados indicam a existência de uma produção artesanal, histórica e pouca tecnologia. A produção é limitada em função do: cultivo da mandioca; processo produtivo; diminuição do envolvimento familiar, consequência da falta de mão de obra e de sucessão empresarial, e pouca assistência técnica em agricultura. Foram identificados vários tópicos relevantes para a facilitação da produção e da comercialização, destacando-se o cooperativismo. Este diagnóstico se mostra relevante para a agroindústria familiar rural, fornecendo indicativos para a melhoria de processos semelhantes e de interesse para os agentes de desenvolvimento empreendedor em fomentarem as melhorias e o maior rendimento da agricultura familiar. Este diagnóstico atendeu a linha de pesquisa de Gestão da Produção Agropecuária e Agroindustrial, do mestrado em Produção e Gestão Agroindustrial da UNIDERP.
\end{abstract}

Palavras-chave: Agricultura Familiar. Mandioca. Produção Familiar. Agroindústria Rural

\begin{abstract}
This technical paper analyzed the socioeconomic and productive conditions of Colonia do Pulador, to understand how the cassava flour production process is. The main productive characteristics are presented, describing the educational and family profile, administrative, productive capacity and a brief discussion about the facilitating and complicating elements of the cassava flour production and commercialization. A qualitative and quantitative research was used, with a field procedure, to understand the investigated reality, with data collection together with family producers, observing the production process and with structured interviews, using a questionnaire, containing demographic data, the property basic infrastructure, production process, commercialization and technical assistance. The 11 producers, in seven flour houses, were interviewed, and the data were analyzed using descriptive statistics. The results indicate the existence of artisanal, historical production and little technology. Production is limited according to: cassava cultivation; productive process; decreased family involvement as a result of a lack of labor and business succession, and; little technical assistance in agriculture. Several relevant topics were identified for the facilitation of production and commercialization, with emphasis on cooperativism. This diagnosis proves to be relevant for the rural family agroindustry, providing indications for the improvement of similar processes and of interest to the agents of entrepreneurial development to foster improvements and the higher income of family farming. This diagnosis met the line of research in Management of Agricultural and Agroindustrial Production, of the master's degree program in Production and Agroindustrial Management at UNIDERP.
\end{abstract}

Keywords: Family Agriculture. Cassava, Family Farm. Rural Agribusiness.

\section{Introdução}

A antiga Fazenda Pulador, no Município de Anastácio, Mato Grosso do Sul, foi colonizada em 1912 pelos imigrantes Nordestinos, a maioria de origem pernambucana que fugia das fortes secas do semiárido. Ao longo desse tempo foi consolidada a Colônia Pulador, que consiste em mais de 20.000 hectares de terras, nas quais se estabeleceram, aproximadamente, 600 famílias (VALÉRIO, 2002).

Apesar da existência de outras colônias próximas,
Caramujo, Chora Chora, a Colônia do Pulador se destaca pela sua formação e pela produção da farinha de mandioca. Com uma característica peculiar, quanto à socialização que é consequência da colonização, em que predomina o convívio familiar, inclusive, no processo produtivo, uma vez que uma família auxilia outra quando da produção da farinha de mandioca, como também todos têm interesse em melhorar as condições de vida na região. A viabilidade econômica da atividade rural precisa ser fortalecida e os atores envolvidos na produção necessitam de retorno financeiro para se manter 
na atividade (SIQUEIRA; SOUZA; PONCIANO, 2011).

A proposta da pesquisa foi diagnosticar as condições socioeconômicas dos produtores rurais de farinha de mandioca da Colônia do Pulador, município de Anastácio, MS, com intuito de gerar subsídios para elaboração de políticas públicas que visem melhoras as condições de vida dos produtores rurais deste objeto e das demais colônias vizinhas.

\section{Desenvolvimento}

Esta pesquisa se pautou na abordagem qualitativa e quantitativa, cuja modalidade se configurou como descritiva realizada in loco, e foram coletadas os dados, informações, identificações em relação ao objeto da pesquisa. O espaço investigado foi a Colônia do Pulador, município de AnastácioMS, localizado a $126 \mathrm{~km}$ da Capital do Mato Grosso do Sul (Campo Grande). A metodologia utilizada para a realização deste trabalho envolveu entrevistas com aplicação de questionários, tendo onze produtores de farinha de mandioca como sujeitos da pesquisa, e sete Casas de farinha como espaços investigados. Foram realizadas sete visitas, no período entre outubro a dezembro de 2015. Em cada visita à localidade foi aplicado o questionário, individualmente, a cada produtor em sua propriedade.

\subsection{Discussões}

A Colônia do Pulador está localizada na área rural do município de Anastácio - MS - distância média do perímetro urbano de $15 \mathrm{~km}$, o acesso ocorre pelas rodovias BR 262, pavimentada e pela MS 170, cascalhada como se pode observar na Figura 1.

Figura 1 - Localização geográfica da Colônia do Pulador, Anastácio, MS, 2015

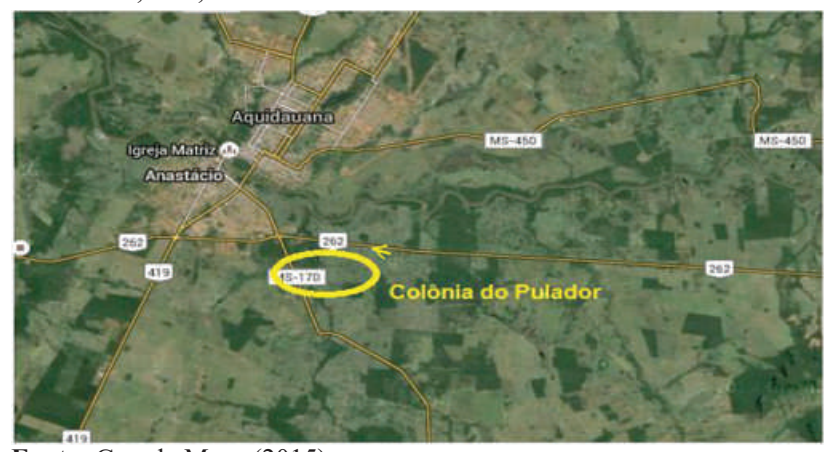

Fonte: Google Maps (2015).

A Colônia do Pulador possui todas as características da agricultura familiar, áreas dos lotes em que são instaladas as casas de farinha, a gestão e mão de obra aplicada na sua operacionalização.

Apesar da existência de outras colônias próximas como a Chora Chora e Caramujo, a Colônia do Pulador se destaca pela sua formação e pela produção da Farinha de Mandioca.

\subsection{Processo de Produção da Farinha de Mandioca}

Acasa de farinha é o local no qual se transforma a mandioca em farinha, ingrediente usado na fabricação de vários alimentos, entre os quais farinha e a fécula de mandioca. Em 1551, o padre jesuíta Manoel da Nóbrega já falava, quando das suas peregrinações pelo Nordeste brasileiro das farinhas, oriundas da mandioca, fabricadas pelos indígenas (GASPAR, 2003).

No período colonial, a farinha de mandioca era usada para a alimentação dos escravos, dos criados das fazendas e nos engenhos, além de servir também como suprimento de viagem para os portugueses. Em algumas regiões, objetivando tornar o alimento menos perecível, misturava-se a farinha de mandioca com a farinha de peixe seco, socada em pilão (GASPAR, 2003). A autora ressalta, ainda, que a farinha de mandioca, ou mesmo a raiz da mandioca são iguarias que, historicamente, fizeram e continuam fazendo parte do cardápio alimentar das famílias brasileiras, principalmente, das populações de menor poder aquisitivo.

Nos processos produtivos das casas de farinha há maneiras diferenciadas de aquisição do produto, nas diversas regiões brasileiras. O processo representado pela figura 2 reflete as dimensões territoriais do trabalho desenvolvido de forma coletiva. Dispondo de uma estrutura de divisão de tarefas e especialização do trabalho bem sistematizada, a linha de produção é um elo entre o findar do trabalho de um indivíduo e a continuidade da tarefa do outro.

Para se obter a farinha de mandioca há maneiras diferenciadas de aquisição do produto, ou seja, não há uma padronização. O apresentado na Figura 2 é modelo utilizado pelos produtores de farinha da Colônia do Pulador.

Figura 2 - Fluxograma para obtenção de farinha de mandioca utilizando prensagem artesanal

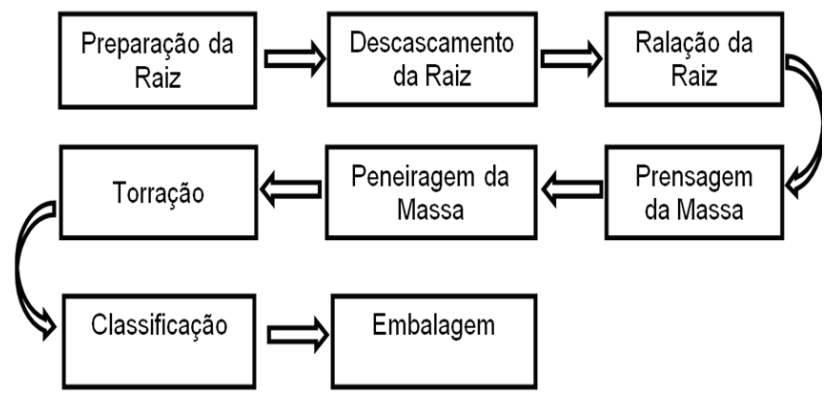

Fonte: dados da pesquisa.

A produção da farinha e outros subprodutos oriundos da raiz da mandioca sela entre os participantes da produção a reafirmação entre os laços, que vão além do caráter produtivo, mas extrapola os laços familiares, da amizade, da confiança, do respeito, da lealdade na pessoa que o contratou e na equipe que toma para si o trabalho em execução.

No processo produtivo, a participação do trabalho feminino restringe a etapa denominada de raspagem, cabendo às mulheres o papel da raspadeira e das tiradeiras de goma. O trabalho masculino está direcionado a outras funções específicas que, normalmente, exigem força e maior destreza, pelos perigos eminentemente altos, são essas: forneiro, 
cevador, prenseiro.

Quanto ao preparo da matéria-prima (raiz de mandioca), as raízes, quando levadas às Casas de Farinha, devem ser lavadas evitando incorporação de materiais indesejados à operação produtiva, o descascamento de raízes é feito manualmente, e essas devem ser lavadas para a retirada de cascas e impurezas ainda remanescentes, para posteriormente serem encaminhadas para o processo de ralação das raízes.

$\mathrm{Na}$ Figura 3 são apresentadas as características das edificações, em que é realizado todo o processo produtivo da transformação da mandioca em raiz para farinha de mandioca, processo produtivo que ocorre de forma artesanal.

Figura 3 - Casa da Farinha, Colônia do Pulador, Anastácio, MS, 2015

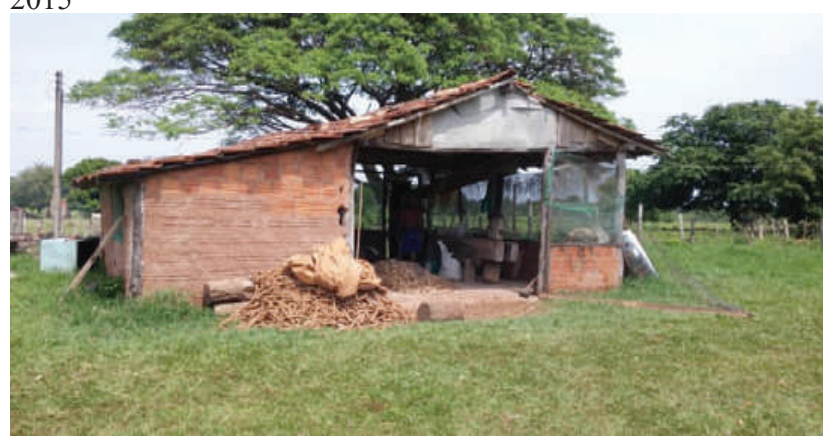

Fonte: os autores.

A ralação das raízes de mandioca é realizada em um ralador constituído de um cilindro de madeira provido de lâminas de aço serrilhadas. As raízes são empurradas em direção ao cilindro por meio de braços de madeira em movimentos alternados, com o propósito de obter uma raspa fina.

Figura 4 - Casa da Farinha, moagem da raiz da mandioca pelo cevador, Colônia do Pulador, Anastácio, MS, 2015

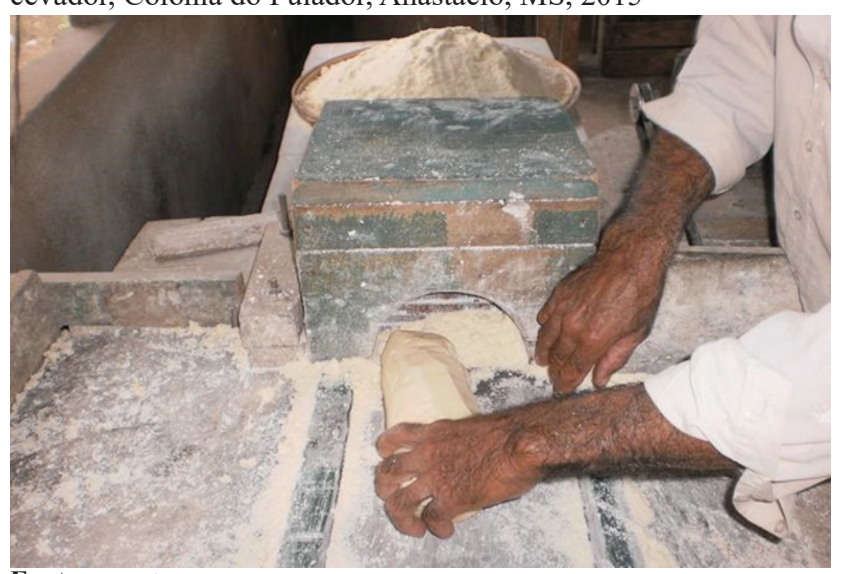

Fonte: os autores.

Processo manual, conforme apresentado na figura 4, a falta da utilização de equipamentos de segurança, como luva especial ou sistema de trava no cilindro, o que acomete muitos trabalhadores em acidentes. A massa obtida, por meio da raspa da mandioca pelo Cevador (responsável pela ralação da raiz de mandioca), possui $67 \%$ de umidade, conforme Pimentel e Cunha (2001). Essa massa é levada para a prensadeira, na qual é condicionado no espaço em formato de cocho, em que ocorre o processo de redução de umidade que é realizado pela pressão de um torriquete, com esforço humano que, em movimentos circulares, faz com que o líquido de cor amarelada, denominado manipueira (palavra de origem indígena), seja extraído da massa (Figura 5). Essa ação ocorre por um período de até oito horas.

Figura 5 - Prensa da Massa da Mandioca, Prenseiro, Colônia do Pulador, Anastácio, MS, 2015

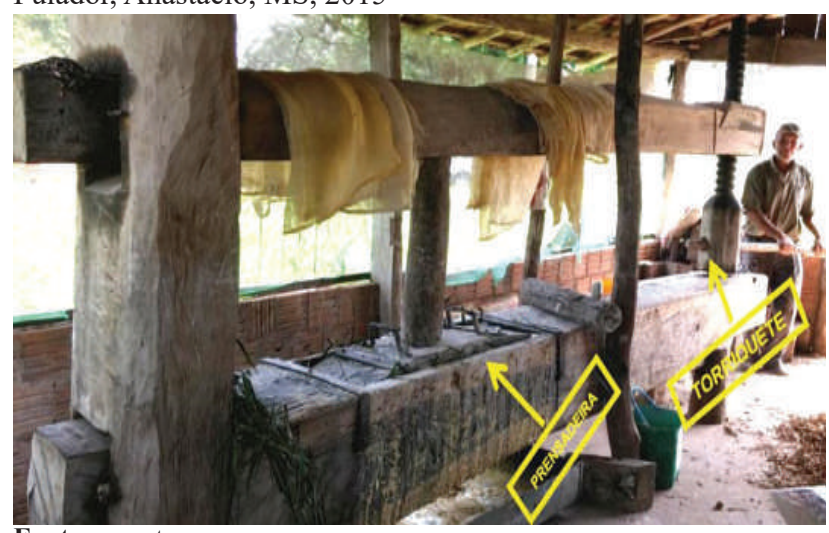

Fonte: os autores.

A manipueira, como se pode observar na figura 6, quando despejada na natureza, provoca a poluição do solo e das águas, causando grandes prejuízos ao meio ambiente e ao homem. Esse despejo pode e deve ser evitado com a utilização de técnicas corretas de manejo da casa de farinha.

Figura 6 - Resíduo tóxico - Manipueira, Colônia do Pulador, Anastácio, MS, 2015

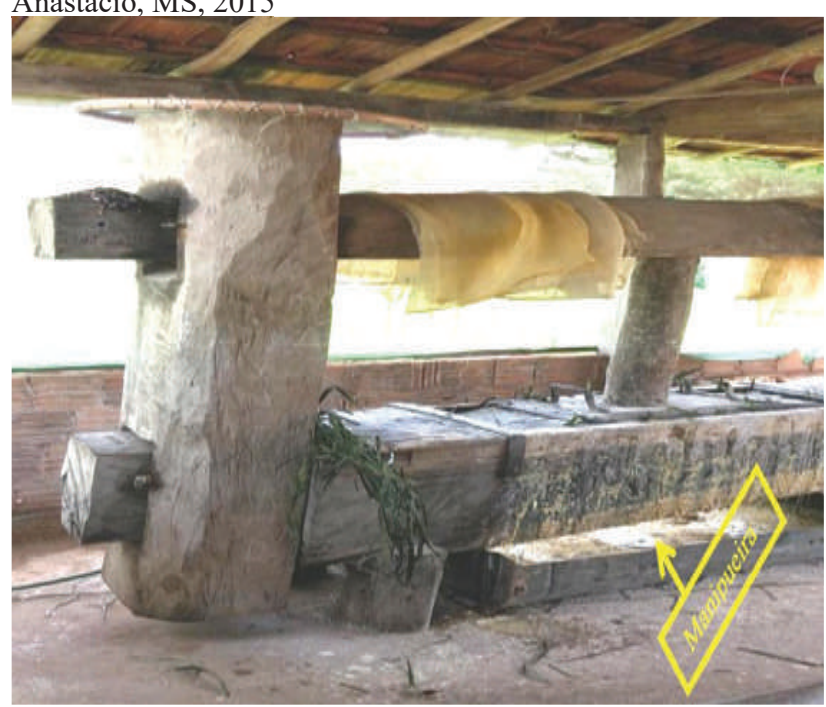

Fonte: os autores.

Ao sair da prensa, a massa obtida está toda encorpada, em formato de torrões como consequência da pressão sofrida na prensa. Para efetuar o esfarelamento, alguns produtores se utilizam de ralador comum ou por intermédio de peneiras, sendo feita a separação da massa que será destinada para produção da farinha, sendo depois acondicionada em cochos apropriados, enquanto a crueira fica retida na peneira, sendo essa um subproduto destinado para alimentação de porcos e galinhas, como se pode observar na figura 7 . 
Figura 7 - Peneiragem dos torrões (Crueira), Colônia do Pulador, Anastácio, MS, 2015

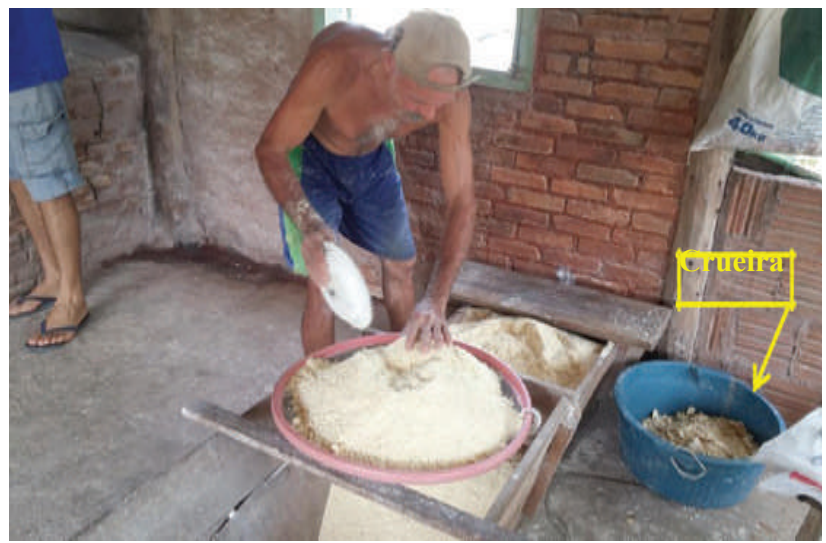

Fonte: os autores.

Após desmanche dos torrões de farinha, a próxima etapa é a torração, processo delicado e preciso, pois determina o teor de qualidade do produto final (Figura 8).

A cor, o sabor e a conservação durante o transporte e armazenamento dependem da fase de torração. Por isso, notoriamente, destina-se um homem na casa de farinha como forneiro, contando a sua experiência e a sua acuidade com a produção.

A torração é realizada com a utilização de uma pá de madeira, com cabo alongado, o processo de torração dura entre 40 a 50 minutos, dependendo do produto desejado, e da intensidade do fogo que é produzido aplicando-se lenha.

Figura 8 - Processo de Torração da farinha de mandioca, Colônia do Pulador, Anastácio, MS, 2015

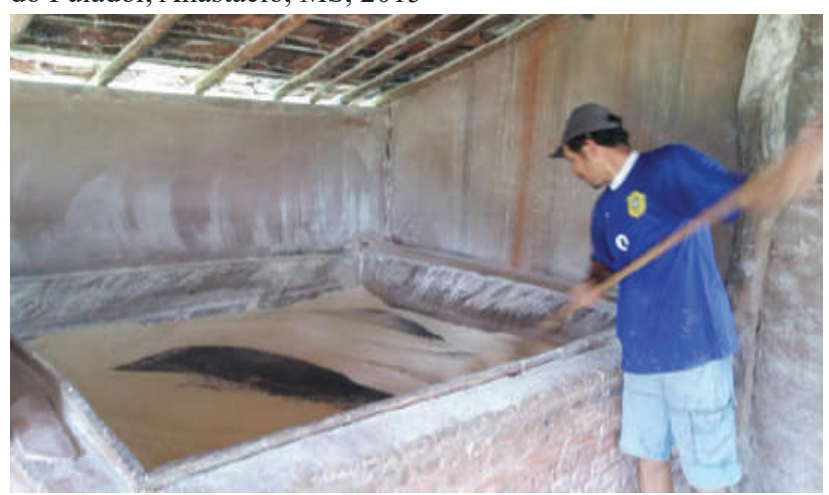

Fonte: os autores.

Após a torrefação da farinha, a próxima etapa é a peneiragem da farinha (Figura 9): após a cocção ou torração, a farinha deve ser passada em peneiras, para promover a separação de algumas partes indesejáveis da farinha - produto final.

As peneiras utilizadas variam conforme sua granulometria que define o tipo de farinha de mandioca que se pretende obter para comercializar.
Figura 9 - Peneiragem da farinha já torrada, Colônia do Pulador, Anastácio, MS, 2015

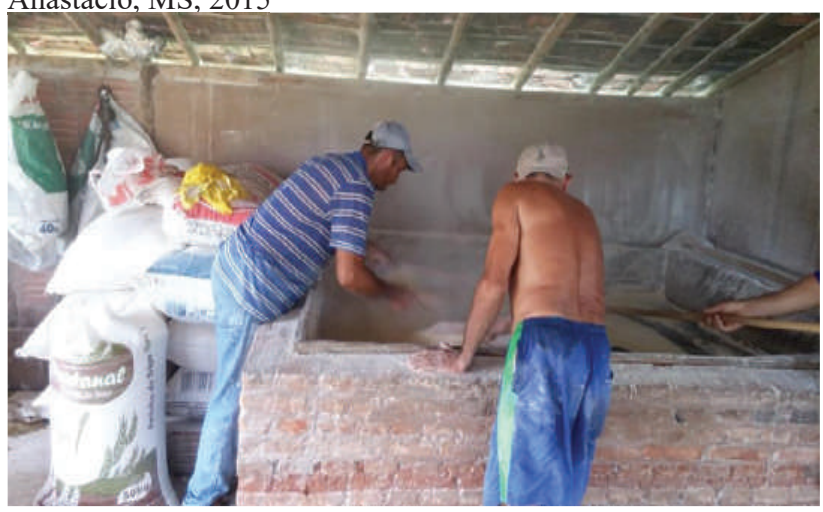

Fonte: os autores.

A próxima etapa do sistema produtivo é o acondicionamento. Depois de classificada, a farinha de mandioca dever ser acondicionada em sacos plásticos ou de aniagem, que devem ser armazenados sobre estrados de madeira em locais não úmidos e ventilados para posterior comercialização, conforme se apresenta na figura 10 .

Figura 10 - Estocagem da farinha já torrada, Colônia do Pulador, Anastácio, MS, 2015

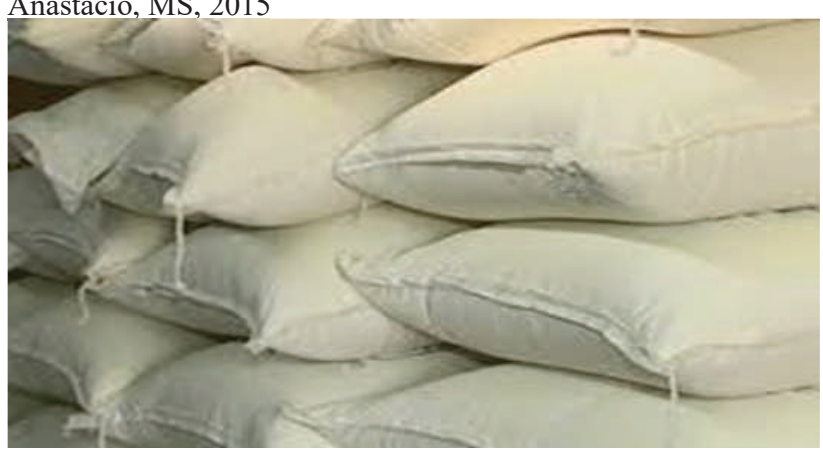

Fonte: os autores.

As casas de farinha, locais nos quais se beneficia a mandioca, garantem emprego e renda para produtores, familiares e demais agentes envolvidos, movimentando a economia das localidades em que estão inseridas. Um grande empecilho para um maior desenvolvimento das casas de farinha é que estes estabelecimentos se caracterizam pela estrutura familiar tradicional, com infraestrutura imprópria aos atuais padrões de higiene e qualidade, equipamentos rudimentares e inexistência de uma gestão capacitada (SANTOS et.al., 2009).

As Casas de Farinha presentes na Colônia do Pulador se aproximam muito do modelo perpetuado no Nordeste brasileiro. São casas de estrutura artesanal com maquinários rústicos, que estão próximos do método tradicional de produção. Tradicional, porque se aproxima em muito da contribuição indígena para o surgimento das Casas de Farinha, sendo pouco tecnificadas: paredes de adobão - tipo de tijolos usados em construções no semiárido Nordestino - paredes de tijolo à vista, chão batido, telhados rústicos.

Os aspectos rústicos e as formas tradicionais na aplicação dos processos produtivos empregados nas Casas de Farinha 
que desenvolvem atividades semi-industriais, nos quais a lenha é a principal fonte energética do sistema produtivo, mesmo sendo economicamente viável, em contrapartida, gera um custo ambiental imensurável.

Outro fator que merece destaque é a não utilização de insumos tóxicos para produção de mandioca, só fazem uso de adubos orgânicos. O cultivo de mandioca sem utilização de agrotóxicos culmina em produtos saudáveis e sem qualquer tipo de contaminante. Essa também contribui para a criação de ecossistemas mais equilibrados, ajudando a preservar a biodiversidade, os ciclos naturais e as atividades biológicas do solo. Além disso, existe outro aspecto da agricultura orgânica que vai além da preservação da qualidade dos produtos ou do meio ambiente. Essa é uma grande aliada da agricultura de baixo volume, como a agricultura familiar.

A aplicação dos princípios agroecológicos, na pequena propriedade rural, consegue aumentar sua sustentabilidade econômico-financeira, aumentando os benefícios para o agricultor, sua independência no uso de energias não renováveis e a preservação de sua identidade cultural e da sua condição de saúde, uma vez que não faz uso de elementos prejudiciais ao homem.

\subsection{Características Sociodemográficas}

Segundo dados coletados da pesquisa, 81,8\% dos produtores de farinha de mandioca são alfabetizados, 9,1\% têm o Ensino Médio incompleto e 9,1\% o Ensino Médio completo. Quanto à faixa etária dos produtores de farinha, esses apresentam idade entre 38 anos a 79 anos.

A quantidade de pessoas na família é baixa, apresentando uma média de duas pessoas por produtor. Esse resultado não difere do apresentado pela pesquisadora Alba (2009), que afirma que a maioria das famílias dos agricultores, 85\%, é composta por três pessoas, esse número baixo de pessoas na família preocupa em função da sucessão familiar no prosseguimento dos negócios, especialmente, se considerar a idade dos produtores, haja vista, que conforme demonstrou a pesquisa, nenhum dos produtores rurais pesquisados afirma possuir sucessor. Segundo Silva (2005), os filhos dos produtores rurais têm mais acesso à educação e oportunidades na zona urbana, e veem nas cidades expectativas de crescimento e de desenvolvimento maiores que no campo. Isso se pode constatar na investigação junto aos produtores rurais de farinha de mandioca, em que $100 \%$ dos entrevistados afirmam que a vontade dos jovens é sair do campo, como também não possuem substitutos para dar continuidade para a produção da fabricação da farinha.

Pode-se constar que quanto ao Estado de origem, mesmo passados mais de 80 anos do início da colonização, ainda são encontrados produtores que nasceram no Nordeste e estão à frente da produção de farinha de mandioca. Dos pesquisados, $54,64 \%$ são nascidos em Pernambuco e Sergipe, e 45,4\% são sul-mato-grossenses, mas descendentes de Nordestinos.

\subsection{Características das propriedades}

As áreas dos lotes das propriedades, nas quais funcionam as casas de farinhas variam de 2 hectares até 20 hectares, sendo que $60 \%$ das propriedades têm área inferior a 10 hectares e $40 \%$ superiores a 10 hectares. Quanto ao tamanho das áreas, 45\% dos produtores ampliaram, desde que receberam suas terras como herança, em decorrência das atividades de produção de farinha de mandioca, e outros $45 \%$ mantêm a área original, e $10 \%$ não informaram. As casas são de alvenaria e são dotadas de sanitários na parte interna do imóvel.

\subsection{Produção e comercialização}

A estrutura de produção segue os mesmos procedimentos artesanais dos últimos sessenta anos. Poucos ajustes foram realizados para atender as exigências do mercado, com pouca diversificação do produto básico. No entanto, observou-se que esta tradição foi um elo de impulso para outras famílias da comunidade, despertando o interesse por este método de produção, e o surgimento de outras unidades farinheiras na região.

Todas as casas de farinha em funcionamento na Colônia do Pulador operam em regime de informalidade, sem registro legal nos órgãos públicos. Pode-se considerar que são artesões e informais.

Esta condição não impede que o produto da Colônia do Pulador tenha o seu espaço nas vendas local e regional. Seu principal destaque é o reconhecimento da sua tradição produtiva artesanal e de relacionamento com a agricultura familiar.

A produção de farinha de mandioca não é homogênea entre as famílias de produtores, mesmo adotando as mesmas técnicas de produção. Valores da produção são expostos no Quadro 1, indicando que a grande maioria produz $200 \mathrm{~kg}$ por semana.

Quadro 1 - Produção de farinha da Colônia Puladora. AnastácioMS. 2015

\begin{tabular}{|c|c|}
\hline Quantidade de Farinha Produzida Semana (kg) & $\%$ \\
\hline 100 & 9,10 \\
\hline 150 & 9,10 \\
\hline 200 & 54,50 \\
\hline 250 & 9,10 \\
\hline 300 & 9,10 \\
\hline 350 & 9,10 \\
\hline Total & $100 \%$ \\
\hline
\end{tabular}

Fonte: dados da pesquisa.

Quanto ao preparo da matéria-prima (raiz de mandioca), todos os produtores afirmaram que em nenhum momento efetuam a lavagem depois de raspar a mandioca. As raízes são levadas para o próximo processo de produção, durante a moagem, e neste momento, o cevador tritura a mandioca, deixando-a em forma de massa.

A produção da mandioca é mais intensa durante os meses 
de março e abril, permanecendo estável nos demais meses do ano, salvo no Inverno da região, junho e julho, quando o clima é mais seco e com menos chuva (Figura 2). O aumento da produção de mandioca, em março e abril, é decorrente da Festa da Farinha no mês de maio, uma tradição anual nos municípios de Anastácio e Aquidauana.

Figura 11 - Produção mensal da farinha de mandioca na Colônia do Pulador, Anastácio, 2015

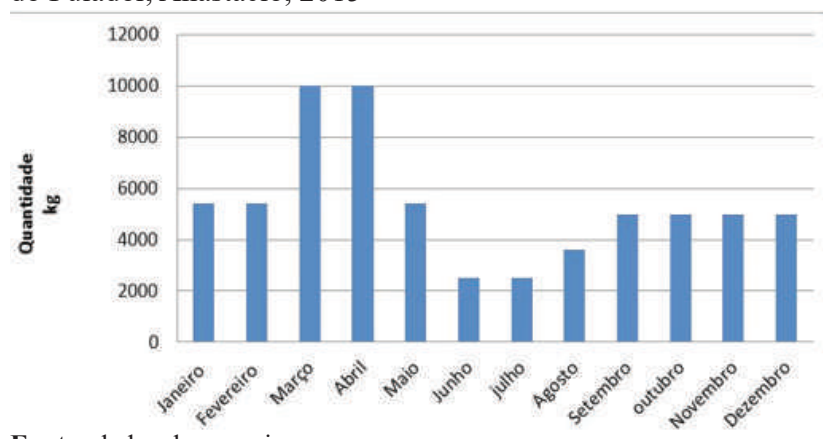

Fonte: dados da pesquisa.

Quanto à produção da raiz de mandioca se observou que a quantidade produzida por hectare de 15 t/ha está abaixo da média nacional de 21,2 t/ha, como também da média do Estado de 21,8 t/ha (IBGE, 2013). Porém, está na média de produção da Região do Pantanal/MS, consequência das características do solo da Colônia do Pulador.

Durante a pesquisa estavam em funcionamento sete casas de farinha, das quais duas adotam o sistema cooperativo familiar, e as outras cinco produzem no sistema produtor individual. A maior parte da produção da farinha é comercializada pelos produtores junto a Cooperativados Produtores Rurais da Região do Pulador - COPRAN, quem tem procurado incentivar a comercialização da farinha.

Considerando que são produtores familiares, a administração dos negócios é realizada sempre por um membro da família. A aquisição de insumos e a negociação com a agroindústria, bem como o recebimento é sempre individual. Poucos conseguem viver, exclusivamente, da produção. Segundo dados, 54,5\% complementam a renda da família com outras rendas, oriundas de aposentadorias e outras não declaradas, e 36,4\% que complementam sua renda com a comercialização de outros produtos agropecuários produzidos na propriedade.

O que se percebeu, em função da quantidade de farinha produzida, e a complementação da comercialização de outros produtos agropecuários para suprir a renda familiar necessária, é que se deve considerar o apoio técnico e o conhecimento atualizado para os produtores. Dessa forma, foram elencadas algumas sugestões recolhidas junto aos produtores, as quais poderão ser implantadas e contribuir para melhorar as condições de produção de mandioca, sendo essas expostas a seguir:

- Promover ações para aumento da produção de farinha, melhorando as condições do produto e de comercialização, para que estimule os mais jovens a darem continuidade para a produção da farinha de mandioca;
- Estimular as formações técnicas e elaboração de plano de negócio para diminuir as incertezas e aprimorar a tomada de decisão da continuidade da produção de farinha;

- Orientar os produtores sobre os cuidados sanitários e higiênicos na manipulação, acondicionamento, conservação, e estrutura dos equipamentos e instalações;

- implementar as práticas de Segurança do Trabalho, diminuindo os riscos de acidentes e o aumento da produtividade;

- Requerer a elaboração de uma marca para identificação da garantia de qualidade e procedência da produção artesanal e agro familiar;

- Estimular a maior participação da mão de obra feminina, no sistema produtivo e de gestão;

- Oferecer novos produtos derivados das sobras de farinha de mandioca, como a massa para tapioca;

- Propor à cooperativa a solicitação de cooperação técnica junto aos agentes de desenvolvimento e no estabelecimento de políticas públicas específicas à farinha de mandioca artesanal; e

- Estimular o cooperativismo junto aos demais produtores da Colônia do Pulador.

\section{Conclusão}

O resultado obtido neste diagnóstico pode ser entendido como parte de um processo para as melhorias necessárias para o sistema produtivo da farinha de mandioca da Colônia do Pulador no município de Anastácio. Deve-se lembrar de que o processo de desenvolvimento, aqui discutido a ser efetivado, só será possível com a participação e comprometimento de todos os agentes envolvidos em uma união entre a sociedade civil e o Poder Público, caso contrário, a produção artesanal da farinha de mandioca do Pulador está fadada a se esgotar em curto prazo de tempo.

\section{Agradecimentos}

Os autores gostariam de registrar e reconhecer o Prof. Dr. Francisco de Assis Rolim Pereira, pela postura humana, generosa, humilde, polida, educada, elegante, honesta, leal, estimulando e encorajando a condução e a orientação desta pesquisa. Faz uma falta insubstituível em nossas vidas.

\section{Referências}

ALBA, R. L. Crédito rural para a agricultura familiar: o perfil dos associados/as da Cresol FCO. Francisco Beltrão: Universidade Estadual do Oeste do Paraná, 2009.

GASPAR, L. Casa de farinha. Fundação Joaquim Nabuco. 2009. Disponível em: <http://basilio.fundaj.gov.br/pesquisaescolar/index. php?option $=$ com_cont ent\&view $=$ article $\&$ id $=531>$. Acesso em: 5 nov. 2020

GOOGLE MAPS. Localização geográfica da Colônia do Pulador Anastácio - MS. [2015]. Acesso em: 5 nov. 2020.

IBGE- Instituto Brasileiro de Geografia e Estatística. Lavouras temporárias e permanentes 2013 - Tabela 21. Disponível em:<http://www.ibge.gov.br/home/ estatistica/economia/pam/2013/default_temp_perm_xls.shtm>. Acesso em: 25 nov. 2020.

PIMENTEL, F. A.; CUNHA, E. T. Pesagem mecânica para obtenção de 
Farinha de mandioca. Acre: Embrapa: CPAFAC, 2001.

SANTOS, E. F. et al. Agroindústria da mandioca: O caminho para a sustentabilidade econômica dos beneficiadores do bairro campinhos em Vitória da Conquista - BA. In: CONGRESSO DA SOCIEDADE BRASILEIRA DE ECONOMIA, ADMINISTRAÇÃO E SOCIOLOGIA RURAL, 47., 2009, Porto Alegre. Anais... Porto Alegre: SOBER, 2009.

SILVA, C.L. Desenvolvimento Sustentável: um conceito multidisciplinar. In: SILVA, C. L.; MENDES, J. T. G. Reflexões sobre o desenvolvimento sustentável: agentes e interações sob a ótica multidisciplinar. Petrópolis: Vozes, 2005. p.11-40.

SIQUEIRA, H.M.; SOUZA, P. M.; PONCIANO, N. J. Café convencional versus café orgânico: perspectivas de sustentabilidade socioeconômica dos agricultores familiares do Espírito Santo. Rev. Ceres, v.58, n.2, p.155160, 2011. doi:10.1590/S0034-737X2011000200004

VALÉRIO, C. Breve história

de Anastácio: a margem esquerda. 